\title{
Neuroendocrine small cell carcinoma of the cervix: A case report
}

\author{
GIOVANNA GIORDANO ${ }^{1}$, TIZIANA D'ADDA ${ }^{1}$, SILVIA PIZZI $^{1}$, NICOLETTA CAMPANINI $^{1}$, \\ GIULIA GAMBINO ${ }^{2}$ and ROBERTO BERRETTA ${ }^{2}$ \\ ${ }^{1}$ Department of Medicine and Surgery, Pathology Unit, University of Parma; \\ ${ }^{2}$ Department of Obsterics and Gynecology, University of Parma, Gramsci, I-43126 Parma, Italy
}

Received January 15, 2020; Accepted February 8, 2021

DOI: $10.3892 / \mathrm{mco} .2021 .2254$

\begin{abstract}
Merkel cell polyomavirus (MCPyV) has been found in patients with Merkel cell carcinoma and respiratory tract infections. Merkel cell carcinoma is a primary aggressive neuroendocrine carcinoma of the skin. It has been demonstrated that MCPyV can be transmitted during sexual activity and may be present in the oral and anogenital mucosa. The aim of the present study was to evaluate whether MCPyV coexisted with HPV in three cases of neuroendocrine small cell carcinoma of the cervix using PCR and immunohistochemical analysis Three cases of NSC of the cervix were identified in the pathology archives of Parma University (Italy). Of these, two cases were associated with an adenocarcinomatous component. A set of general primers from the $\mathrm{L} 1$ region (forward, $\mathrm{L} 1 \mathrm{C} 1$ and reverse, $\mathrm{L} 1 \mathrm{C} 2$ or L1C2M) was PCR amplified to detect the broad-spectrum DNA of genital HPV. The presence of MCPyV was investigated via immunohistochemistry using a mouse monoclonal antibody against the MCPyV LT antigen and through PCR analysis to separate viral DNA. HPV DNA was present in all three neuroendocrine carcinomas and in the adenocarcinoma component of the two mixed cases. None of the cases were immunoreactive to CM2B4 and did not contain viral DNA in either their neuroendocrine or adenocarcinomatous component. Whilst it is difficult to draw definitive conclusions from such a small sample size, these data suggested that MCPyV does not coexist with HPV in the cervix. However, in the present study, the absence of detectable MCPyV may have been due to the presence of a genotype that was not detected by the primers used in the PCR analysis or by the antibody used for the immunohistochemical study. MCPyV microRNA may also have been present, inhibiting LT expression. Additional studies with larger cohorts and more advanced molecular
\end{abstract}

Correspondence to: Professor Giovanna Giordano, Department of Medicine and Surgery, Pathology Unit, University of Parma, 14 Viale A., Gramsci, I-43126 Parma, Italy

E-mail: giovanna.giordano@unipr.it

Key words: neuroendocrine small cell carcinoma, merkel cell polyomavirus, human papilloma virus, immunohistochemistry, polymerase chain reaction biology techniques are required to confirm the hypothesis of the current study.

\section{Introduction}

Neuroendocrine neoplasms (NENs) are considered to be composed of cells with characteristics similar to those of the normal diffuse neuroendocrine system, which consists of cells that are a combination of hormone-producing endocrine and nerve cells, scattered throughout the body (for example gastroenteropancreatic, the enteroendocrine hormonal signaling system; respiratory and urogenital systems; paraganglia; adrenal medulla; skin; thymus; heart; middle ear; and other tissues). NENs are a wide heterogeneous family of neoplasms in which neuroendocrine differentiation is demonstrated by the presence of neurosecretory granules in the cytoplasmic component in electron microscopy analysis and in immunohistochemistry for positivity to neuroendocrine markers, including synaptophysin, chromogranin, CD56 and NSE (1). In humans, NENs are typically located in the gastrointestinal tract, the pancreas, and the lungs and are subdivided into well-differentiated and poorly differentiated NENs (2).

In 1996, the College of American Pathologists and the National Cancer Institute suggested reduction in the number of terms used to describe neuroendocrine tumors of the cervix, introducing a classification system of 4 categories: Typical (classical) carcinoid tumor, atypical carcinoid tumor, large cell neuroendocrine carcinoma and small (oat) cell carcinoma (3).

The current WHO Classification of neuroendocrine tumors of the female genital originating in the cervix suggests a terminology similar to that used for gastro-entero-pancreatic neuroendocrine tumors. Thus, according to this classification, tumors originating in the female genital tract can be classified as: Low grade neuroendocrine tumors (grade 1 and grade 2) and high grade neuroendocrine carcinoma, with small and large cells (4). Small Cell Neuroendocrine carcinoma (SCNEC) can be found anywhere in the gynecological tract, but is most commonly observed in the cervix (4). The causative agent underlying the development of this malignancy is Human Papilloma Virus (HPV) (5-7).

Merkel cell carcinoma (MCC) is a rare primary cutaneous neuroendocrine carcinoma (8). Factors involved in the development of MCC include the Merkel cell polyoma virus (MCPyV), a weakened immune system and exposure to ultraviolet radiation $(9,10)$. MCPyV has also been observed in respiratory 
tract secretions (11-14) and it has been demonstrated that it can be transmitted during sexual activity. In addition, MCPyV has been detected in the oral and ano-genital mucosa of human immunodeficiency virus-positive patients $(15,16)$. Moreover, this virus has been found in a series of the most common squamous cervical carcinomas in Japanese patients (17).

These findings prompted the present study into the investigation of the co-presence of MCPyV and HPV in three cases of SCNEC of the cervix, using both immunohistochemical and molecular analyses.

\section{Materials and methods}

Patients. Three cases of SCNEC of the cervix were identified in the pathology archives of Parma University (Italy).

Neuroendocrine differentiation was recognized by morphological analysis and immunohistochemical findings.

In all cases, the diagnosis had been made prior to a small cervical biopsy and then, in two of these cases, on macroscopic and microscopic examination of the hysterectomy with bilateral annessiectomy specimens and in the remaining case on a conization specimen.

The surgical specimens were fixed in $10 \%$ neutral buffered formalin for a routine light microscopic examination. Sections of neoplasms were submitted for histological examination and the samples were embedded in paraffin. Then $3-\mu \mathrm{m}$ sections were cut and stained with hematoxylin-eosin.

Immunohistochemical analysis. For immunohistochemical analysis, after deparaffinization and rehydration, sections were treated with $3 \%$ hydrogen peroxidase for $5 \mathrm{~min}$. For antigen retrieval, sections were treated with $\mathrm{pH} 9$ Tris-EDTA buffer for $30 \mathrm{~min}$ in a water-bath at $98^{\circ} \mathrm{C}$. The following primary antibodies were used: MCPyV large T-antigen (clone CM2B4; mouse monoclonal antibody, 1/50; Santa Cruz Biotechnology. Inc.) Ki67 (clone MIB-1; mouse monoclonal antibody, 1/100; Dako: Agilent Technologies, Inch.) P63 (clone 4A4, mouse monoclonal antibody; ready to use; Ventana Medical System, Inc.) CD56 (clone MRQ-42; rabbit monoclonal primary antibody, ready to use; Ventana Medical System, Inc.), TTF-1 (clone 8G7G3; mouse monoclonal antibody; ready to use, Ventana Medical System, Inc.), P40 (clone SPBC28; mouse monoclonal antibody; ready to use; Ventana Medical System, Inc.), P53 (clone DO-7; mouse monoclonal antibody; ready to use, Ventana Medical System, Inc.), cytokeratin 20 (clone SP33; rabbit monoclonal antibody; ready to use; Ventana Medical System, Inc.), cytokeratin CAM 5.2 (clone CAM 5.2; mouse monoclonal antibody; ready to use; Ventana Medical System, Inc.), chromogranin A (clone LK2H10; mouse monoclonal antibody; ready to use; Ventana Medical System, Inc.), synaptophysin (clone SP11; rabbit monoclonal antibody; ready to use, Ventana Medical System, Inc.).

All sections were immunostained with automatic immunostaining Benchmark Ultra-Roche Diagnostics.

For incubation with antibodies MCPyV, TTF-1, P40, synaptophysin an HRP Polymer-Optiview DAB Detection kit, was used for detection (Ventana Medical System, Inc.), whereas an HRP Polymer-Ultraview Universal DAB Detection kit was used for detection of binding of all other antibodies, both according to the manufacturer's protocol.
Diaminobenzidine was used for development of staining, and the sections were counterstained with hematoxylin. For immunohistochemical study a histological section of cutaneous Merkel cell carcinoma of the neck from a male 71 year old man and a histological section of adenocarcinoma of large bowell from female 61 years old patient, identified in the pathology archives of Parma University (Italy), were used respectively as external positive (Fig. 1A and B) and negative controls, to verify the presence of $\mathrm{MCPyV}$ in our neoplasms.

Molecular analysis. PCR was used to evaluate the presence of HPV and MCPyV DNA in the neoplasms. For DNA extraction, 4- $\mu \mathrm{m}$ histological sections were stained with hematoxylin and examined under a stereomicroscope. Neoplastic areas were manually microdissected using sterile scalpels, then suspended in a buffer for tissue lysis (Tris-HCl $50 \mathrm{mM}$, pH 9, 1 mM EDTA $\mathrm{pH} 8.0,0.5 \%$ Tween-20, 5\% Chelex 100), and incubated overnight with Proteinase $\mathrm{K}(0.4 \mathrm{mg} / \mathrm{ml})$ at $55^{\circ} \mathrm{C}$. After enzyme inactivation by $10-\mathrm{min}$ of boiling, the DNA extracted was directly used in the PCR mix without further purification. As described by Li et al (18), extracted DNA was PCR amplified using a set of general primers ( $1 \mathrm{C} 1 / \mathrm{L} 1 \mathrm{C} 2+\mathrm{C} 2 \mathrm{M})$ designed to match the $\mathrm{L} 1$ region of the conserved region amongst the different HPV genotypes, in order to detect a broad spectrum of genital HPV DNAs (including HPV types 6, 11, 16, 18, 31, 33, 39, 45, 51, 52, 56, 58 and 59) (Table I). Conventional qualitative PCR analysis was performed as follows: $95^{\circ} \mathrm{C}$ for $7 \mathrm{~min}$, $94^{\circ} \mathrm{C}$ for $1 \mathrm{~min}, 40-47^{\circ} \mathrm{C}\left(1^{\circ} \mathrm{C}\right.$ increase each cycle $)$ for $1 \mathrm{~min}$ and $72^{\circ} \mathrm{C}$ for $1 \mathrm{~min}$ for 8 cycles; then $94^{\circ} \mathrm{C}$ for $1 \mathrm{~min}, 48^{\circ} \mathrm{C}$ for $1 \mathrm{~min}$ and $72^{\circ} \mathrm{C}$ for $1 \mathrm{~min}$ for 35 cycles; and a final extension step at $72^{\circ} \mathrm{C}$ for $7 \mathrm{~min}$. A negative (sterile water) and a positive [DNA of a high-grade squamous intraepithelial lesion (H-SIL) HPV-related] controls were included in the amplification run. The presence of PCR products of the correct size (243-262 bp) was confirmed by $2 \%$ agarose gel electrophoresis.

DNA extracted from the neoplastic tissues were tested for PCR amplification of MCPyV DNA using a specific primer set, as described previously (19) (Table I). Conventional qualitative PCR was performed as follows: 35 cycles of $1 \mathrm{~min}$ at $94^{\circ} \mathrm{C}$, $1 \mathrm{~min}$ at $56^{\circ} \mathrm{C}$ and $1 \mathrm{~min}$ at $72^{\circ} \mathrm{C}$, followed a final extension step at $72^{\circ} \mathrm{C}$ for $10 \mathrm{~min}$. A negative (sterile water) and a positive (DNA of a MCC MCPyV-positive, of the neck from a male year old man) controls were included in the amplification run. The presence of PCR products of the correct size (153 bp) was verified by $2 \%$ agarose gel electrophoresis.

\section{Case reports}

Case 1. A 42-year-old Caucasian woman, para 3, gravida 3, with a history of abnormal cervical-vaginal cytology due to the presence of cervical intraepithelial neoplasia (CIN 3, H-SIL) and cervical glandular intra-epithelial neoplasia, underwent conization. On the histological examination, the conization specimen showed an infiltrating, well-differentiated cervical adenocarcinoma (Fig. 2A), H-SIL and a neoplasm characterized by a trabecular and nodular growth pattern, presenting with focal necrosis, accounting for $1 \%$ of neoplastic mass. Peri-tumoral and intra-tumoral flogistic reaction was absent.

The neoplastic cells were round with ovoid nuclei, finely granular chromatin and clearly nucleoli (Fig. 2B). 
Table I. Primer sequences used for HPV and MCPyV PCR amplification.

A, HPV, amplicon size 243-262 bp, Li et al (18)

Primer Sequence (5'-3')

$\begin{array}{ll}\text { L1C1 } & \text { CGTAAACGTTTTCCCTATTTTTTT } \\ \text { L1C2 } & \text { TACCCTAAATACTCTGTATTG } \\ \text { LiC2M } & \text { TACCCTAAATACCCTATATTG }\end{array}$

B, MCPyV, amplicon size 153 bp, Alvarez-Argüelles et al (19)

\begin{tabular}{ll}
\hline MCPyV-1 & CAACAGAGGGCTTTGGGTAAA \\
MCPyV-2 & AAGTGTCAGGCCAACCTATGGAA \\
\hline
\end{tabular}

HPV, human papilloma virus; MCPyV, merkel cell polyomavirus.

Immunohistochemical analysis revealed that the small cell component was positive for neuroendocrine markers, such as NSE, synaptophysin (Fig. 2C), chromogranin A (Fig. 2D) and for CAM5.2 (epithelial marker) (Fig. 2E), but they were negative for TFF1, p63 and p40 both. Well-differentiated cervical adenocarcinoma instead was negative for both all neuroendocrine markers, and for TFF1, p63 and p40 (data not shown).

The mitotic index was high [20 mitoses/10 (high-power fields) (HPF)] and $>25 \%$ intra-nuclear positivity expression for the proliferation marker ki 67 was observed.

In addition, p16 immunoreactivity and PCR analysis demonstrated that all components of the neoplasm were associated with an HPV infection (Fig. 3A). Thus, the microscopic characteristics, in association with the immunohistochemical and molecular findings, were conclusive of a final histological diagnosis of SCNEC of the cervix, associated with H-SIL, a well-differentiated cervical adenocarcinoma and HPV infection. Conversely, immunohistochemical expression for $\mathrm{CM} 2 \mathrm{~B} 4$ was negative, and $\mathrm{MCPyV}$ DNA was not found in PCR analysis (Fig. 3B) in either the neuroendocrine or adenocarcinomatous components. A total hysterectomy with bilateral salpingo-oophorectomy and pelvic lymphadenectomy was performed to establish the stage of the neoplasm. On macroscopic and microscopic analyses, all the specimens were unremarkable and free from neoplasms.

In addition, abdominal ultrasound, chest X-ray, thoracic and abdominal computed tomography and bone scans were unremarkable.

Therefore, the final diagnosis was primary cervical SCNEC with PTla NO MO stage of at diagnosis.

Following radical hysterectomy with lymph-nodes dissection, the patient received chemotherapy $\left(80 \mathrm{mg} / \mathrm{m}^{2}\right.$ and etoposide $100 \mathrm{mg} / \mathrm{m}^{2}$ repeated for two cycles of treatment), followed by the administration of carboplatin (area under the carboplatin plasma concentration vs. time curve $=5$ ), Taxol $175 \mathrm{mg} / \mathrm{m}^{2}$ for two cycles and pelvis radiation of $50 \mathrm{~Gy}$ and of the lymph nodes ( $45 \mathrm{~Gy}$ ) to L1.

A total of 2 years after diagnosis, surgery, chemotherapy and radiotherapy, the patient is free of the disease.
Case 2. An 81-year-old Caucasian woman, para 2, gravida 2, was referred for postmenopausal bleeding which had lasted 7 months'. Gynecological examination, trans-vaginal echography and colposcopy revealed an exophytic fungating red to tan mass that obscured the cervical os. On histological examination, the lesion was composed of nests and cords of small blue neoplastic cells with round or ovoid nuclei (Fig. 4A), finely granular chromatin, small nucleoli and a high mitotic rate (Fig. 4B), accounting for 18 mitoses/10 HPF with $>20 \%$ intranuclear expression of Ki-67. Peri-tumoral and intra-tumoral flogistic reaction was absent. On immunohistochemical analysis, the neoplastic cells expressed synaptophysin (Fig. 4C), CD 56 (Fig. 4D), chromogranin A and CAM5.2 (Fig. 4E), and p16, but were negative for TFF1, p63 and p40.

Pre-opertaive contrast-enhanced computed tomography (CT) of the abdomen and pelvis revealed the presence of a large ulcerated exophytic cervical lesion, measuring $4 \mathrm{~cm}$ in its lagest diameter. Magnetic resonance imaging (MRI) of the abdomen confirmed these findings, identifying large uterine cervical neoplasm. There was no evidence of mass or metastatic disease in the chest, bone or brain on CT scan. The pre-operative Positron Emission Tomography (PET) was not performed.

The patient underwent surgery and total radical hysterectomy with bilateral salpingo-oophorectomy, pelvic and para-aortic lymph node dissection. Macroscopic examination of the surgical specimen revealed the presence of a cervical large exophytic lesion, that was partially ulcerated, measuring $4.7 \times 4 \mathrm{~cm}$, which entirely obscured the cervical os. On sectioning, the lesion involved the endocervix and had replaced its wall. The endometrium, fallopian tubes and ovaries were grossly unremarkable in both specimens. Histopathological examination confirmed the pre-operative diagnosis of SCNEC, with numerous vascular tumor emboli [(stage pT1b2, LVI (+)]. In addition, the neoplastic cells exhibited over-expression of p16 (Fig. 4F) and revealed the presence of HPV DNA (Fig. 3A). Conversely, the neoplastic elements did not express TTF-1, estrogen, progesterone receptors or MCPyV (Fig. 4G). Furthermore, PCR amplification did not show the presence of MCPyV DNA (Fig. 3B). These findings confirmed the diagnosis of primary SCNEC of the cervix associated with HPV with pT1 b2 N0 M0, with numerous vascular tumor emboli.

Conversely, post-operative PET showed many hepatic metastatic lesions.

The patient received carboplatin (area under the carboplatin plasma concentration vs. time curve $=4$ ) and Taxol $\left(60 \mathrm{mg} / \mathrm{m}^{2}\right)$ for two cycles. At 6 months after hysterectomy with salpingo-oophorectomy and chemotherapy, the succumbed to the disease due to the development of diffuse metastatic lesions.

Case 3. An 83-year-old Caucasian woman, para 3, gravida 3, was referred for postmenopausal bleeding which had lasted 8 months' duration. Gynecological examination, colposcopy and transvaginal echography revealed a hemorrhagic cervical mass, measuring $5 \mathrm{~cm}$, which was biopsied. Histopathology al examination revealed the presence of a malignant epithelial tumor composed of cords and trabecula. Peri-tumoral and intra-tumoral flogistic reaction was absent. The neoplastic 

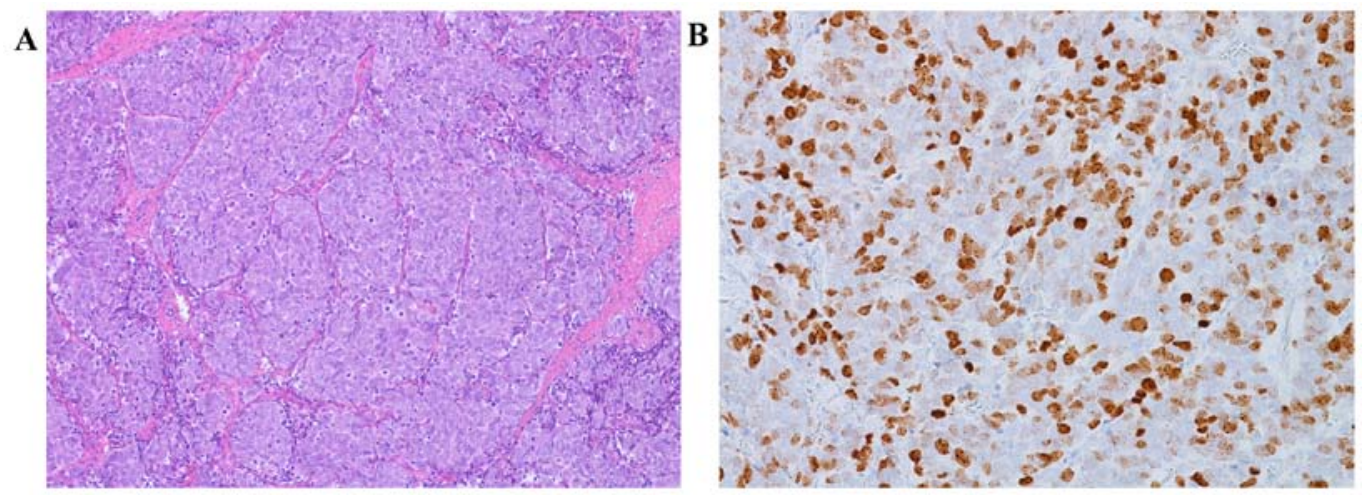

Figure 1. Histological section of an Merkel cell carcinoma used as positive control for PCR analysis and immunohistochemical study. (A) Under microscopic examination, the neoplasm exhibited a nodular pattern that was composed of small blue neoplastic cells (magnification, x100). (B) The neoplastic cells exhibited nuclear positivity for the CM2B4 antibody (magnification, $\mathrm{x} 200$ ).

elements were oval to spindle-shaped with hyperchromatic nuclei. The cytoplasm was scant (Fig. 5A). The mitotic index was high and accounting for 16 mitoses/10 HPF and $>20 \%$ intranuclear expression of Ki-67. Individual cell necrosis with karyorrhexis and karyolysis was visible, but not particularly extensive (Fig. 5A).

In addition, there was a well-differentiated cervical adenocarcinomatous component (Fig. 5B). Immunohistochemistry revealed positivity for chromogranin A (Fig. 5C), synaptophysin (Fig. 5D), and CAM 5.2 (Fig. 5E). Diffuse and marked positivity for P16 protein was observed in both the neuroendocrine (Fig. 6A) and in the adenocarcinomatous component (Fig. 6B). The tumor cells did not express TTF-1, estrogen, progesterone receptors, p63, p40 (data not shown) and in either the neuroendocrine MCPyV (Fig. 6C) or adenocarcinomatous components (Fig. 6D). Moreover, the adenocarcinomatous component was negative for all neuroendocrine markers.

In addition, PCR amplification did not reveal the presence of MCPyV DNA (Fig. 2B). These findings confirmed the diagnosis of a primary SCNEC that was not associated with MCPyV. Based on the PCR analysis, the neoplastic element cells exhibited the presence of HPV DNA, in both the neuroendocrine and adenocarcinomatous components (Fig. 3A). Pre-operative contrast-enhanced CT of the abdomen and pelvis revealed the presence of a large exophytic uterine cervical lesion, measuring $5.5 \mathrm{~cm}$ in its larger diameter. MRI of the abdomen confirmed these findings and revealed a large uterine cervical neoplasm. There was no evidence of mass or metastatic disease to the chest, bone, or brain on CT scan. Pre-operative Positron Emission Tomography (PET) was not performed.

A total hysterectomy with bilateral salpingo-oophorectomy and pelvic lymphadenectomy were performed. Macroscopic examination of the surgical specimens identified a large ulcerated exophytic cervical lesion, measuring $5.5 \times 3.5 \mathrm{~cm}$ that partially obscured the cervical os. On sectioning, the lesions involved the endocervix and had replaced its wall.

The endometrium, fallopian tubes and ovaries were grossly unremarkable. On histological examination, the neoplasm was composed of a SCNEC with oval to spindle-shaped hyperchromatic nuclei and a differentiated cervical adenocarcinomatous component. All lymph nodes were free from metastases. These findings confirmed a diagnosis of primary SCNEC of the cervix associated with HPV, stage pT1-b2-N0-M0, with prominent intravascular and perineural invasion (LVI+). Post-opertative PET showed many metastatic abnormal hypermetabolic lesions in the liver and lungs.

The patient did not receive post-operative treatment and succumbed to diffuse metastatic lesions 1 month after.

\section{Discussion}

Neuroendocrine tumors arise from the hormone-producing cells of the body's neuroendocrine system, which consists of cells that are a combination of hormone-producing endocrine and nerve cells. These neoplasms can most commonly be found in the gastrointestinal tract, pancreas $(20,21)$ and lungs $(22)$. Less frequent locations of neuroendocrine tumors include the urinary system, male genital organs, female genital organs, head, neck and breast (23).

SCNECs are rare malignancies accounting 1-3\% of all cervical tumors $(24,25)$. In line with small cell lung cancer, SCNEC of the cervix is associated with an aggressive and often fatal clinical course (26), which is considerably worse compared with that of squamous carcinoma and adenocarcinoma (27). This malignancy metastasizes early to the lymph nodes and then to distant organs. Widespread dissemination may involve the bones, liver, lung and other soft tissues (27). Moreover, brain metastases have been reported to be associated with lung metastases (28).

SCNECs are composed of a monotonous population of small round or fusiform cells with scant cytoplasm and hyperchromatic nuclei, finely granular chromatin and non-prominent nucleoli, growing in diffuse or more rarely, nested or trabecular pattern. Single cell infiltration of the stroma may also observed. Nuclear molding and crush artifacts are common and are helpful for diagnosis. Necrosis and apoptosis are a common and lymphatic invasion is frequently extensive. SCNECs may coexist with other more typical cervical carcinomas, such as squamous cell carcinomas or adenocarcinomas, adenocarcinoma in situ and cervical intraepithelial neoplasia $(29,30)$.

Several studies have reported that the presence of other subtypes of cervical carcinoma in SCNEC does not improve the prognosis, which remains significantly worse compared with pure cervical squamous cell carcinomas and adenocar- 
A
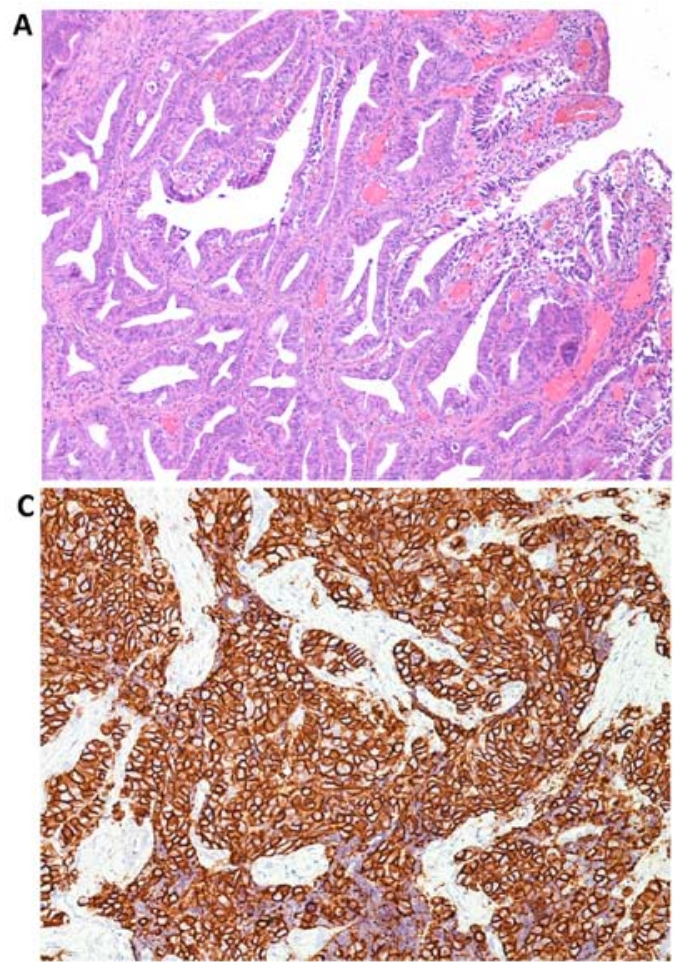

B
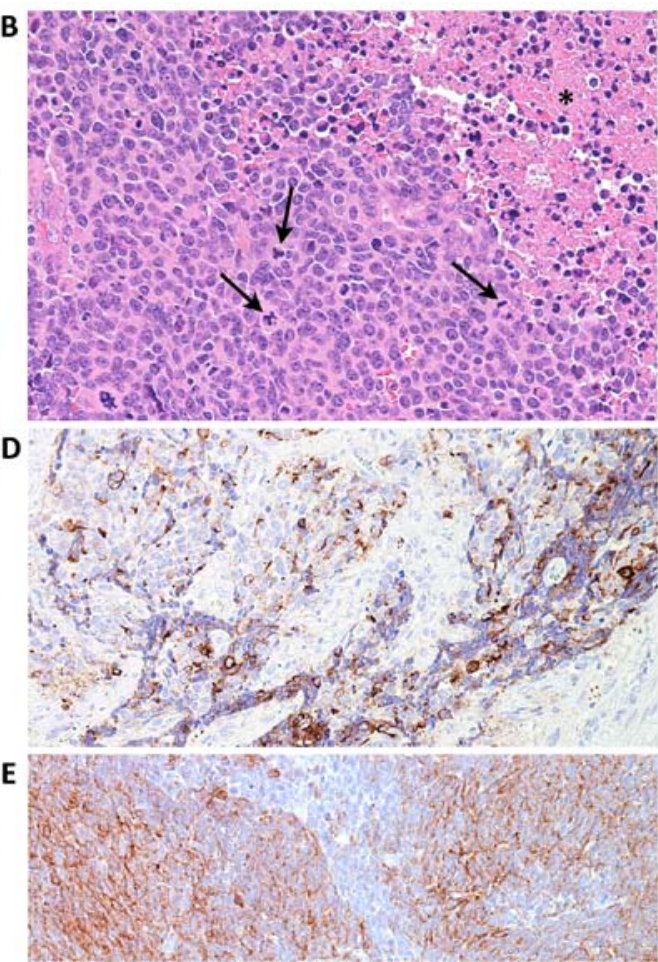

Figure 2. Case 1. Under microscopic examination, the neoplasm was composed of (A) a well-differentiated cervical adenocarcinomatous component (magnification, x100) and (B) a neuroendocrine component characterized by small cells with focal necrosis (asterisk), round or ovoid nuclei with finely granular chromatin, evident nucleoli and numerous mitoses (arrows) (magnification, x200). (C) The neuroendocrine component exhibited intense membrane immunoreactivity for synaptophysin (magnification, x200). (D) Granular, dot-like perinuclear citoplasmic positivity was demonstrated for chromogranin (magnification, x200) and (E) diffuse membrane immunoreactivity for CAM 5.2 was exhibited (magnification, x200).

cinomas (31). These data are in agreement with two of these cases in the present report (cases 2 and 3) in which both patients underwent hysterectomy with salpingo-oophorectomy but developed diffuse metastatic lesions and succumbed to the disease within a few months after surgery. Moreover, prominent lympho-vascular invasion was observed in both cases in the histological examination of radical hysterectomy with bilateral salpingo-oophorectomy specimen, explaining the rapid demise after a few of diagnosis.

According to previous studies, the tumor stage, at diagnosis, in these patients would have been more advanced (pT1b2, M1, LVI +) than in a patient (case 1, pt1a) who was still alive 2 years after diagnosis $(32,33)$. SCNECs should be distinguished from primary and metastatic small blue-cell tumors, such as poorly differentiated squamous cell carcinomas, undifferentiated carcinomas of the lower uterine segment, primary lymphomas of the cervix and neuroendocrine metastatic tumors of a different primary origin (such as the lung), to the cervix. For all three cases of the present work, poorly differentiated squamous cell carcinomas can be distinguished from small cell neuroendocrine carcinomas due to the fact that they lack certain morphological characteristcs on microscopic examination that typically characterize small cell cervical cancer, including nuclear molding and non-diagnostic (or crush) artifacts. In addition, immunoreactivity to p63 and p40 may be useful in differentiating SCNEC from squamous cell carcinoma since these markers are consistently expressed in squamous cell carcinomas, but are negative in SCNEC. Moreover, whilst p63 expression may be observed in SCNEC (34), negativity to p40 excludes the diagnosis of

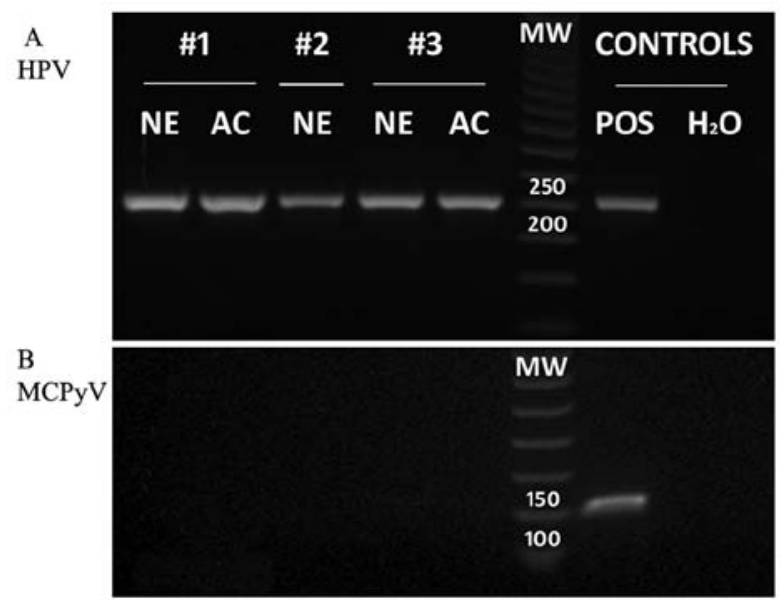

Figure 3. Molecular analysis of the three cases. (A) Results of qualitative PCR amplification for HPV DNA using a set of general primers for the L1 region (18). Strong positivity was demonstrated in all three neoplasms, both in the NE and in the AC component. (B) Results of qualitative PCR amplification for MCPyV DNA, using a set of specific primers (19). Negativity was demonstrated in all neoplasms. HPV, human papilloma virus; NE, neuroendocrine; $\mathrm{AC}$, adenocarcinomatous component; MCCPyV, merkel cell poliomavirus virus; $\mathrm{MW}$, molecular weight standard; $\mathrm{POS}$, positive control; $\mathrm{H}_{2} \mathrm{O}$, sterile water used as the negative control.

squamous cell carcinoma, as p40 is consistently negative in neuroendocrine neoplasms at any site $(35,36)$. Neuroendocrine markers with morphological evaluation may assist in the differential diagnosis of SCNEC and non-keratinizing squamous cell HPV-related carcinomas. 

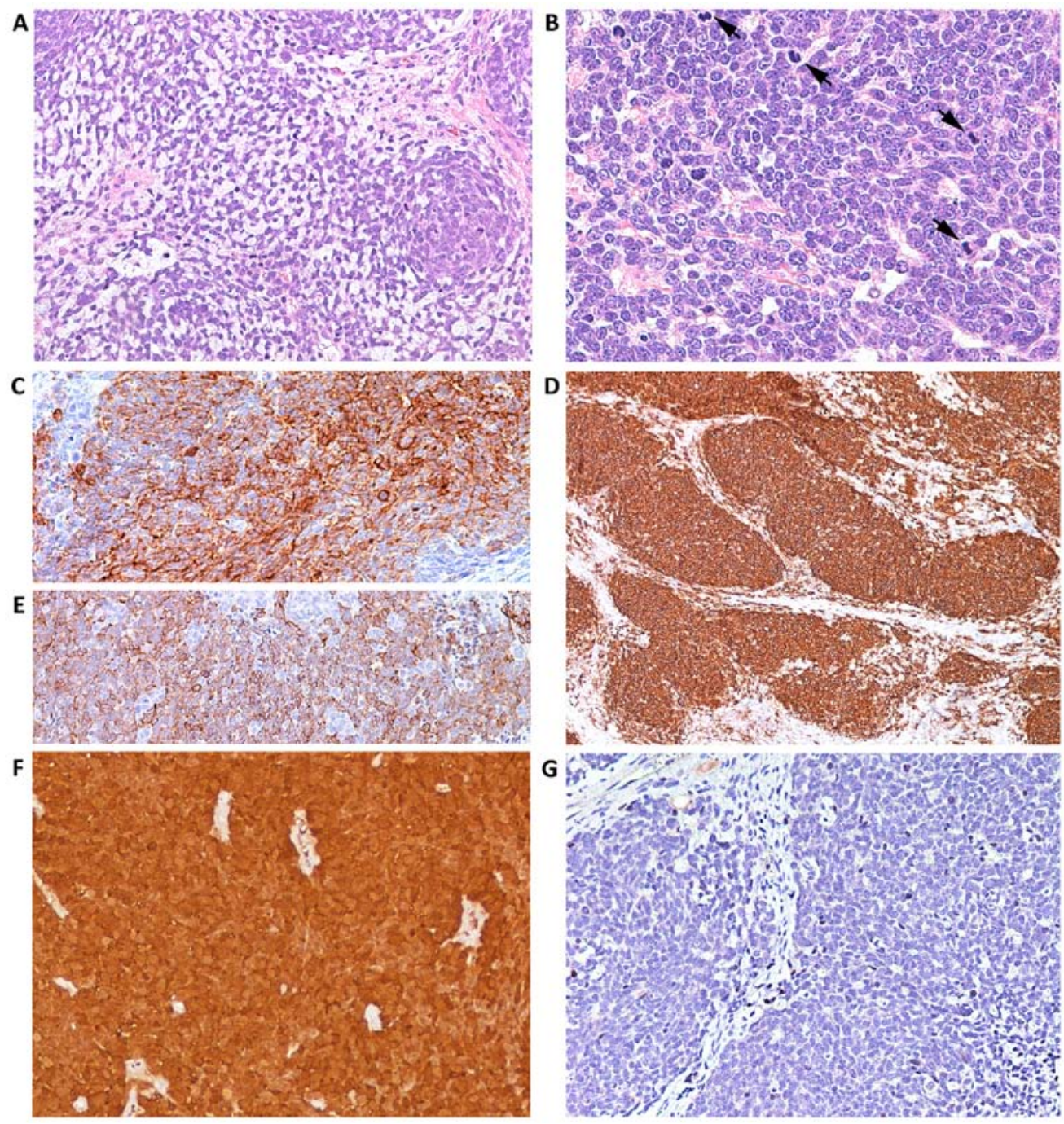

Figure 4. Case 2. Following histologic examination, the lesion exhibited (A) nests and cords of small blue neoplastic cells (magnification, x200), with (B) round or ovoid nuclei, finely granular chromatin, small nucleoli and a high mitotic rate (arrows) (magnification, x400). (C) Neoplastic cells exhibited membrane immunoreactivity for synaptophysin (magnification, x400). (D) CD56 (magnification, x100) and (E) CAM5.2 (magnification, x200) staining confirmed the lesion was neuroendocrine in nature. Immunohistochemical analysis revealed $(\mathrm{F})$ diffuse cytoplasmic and nuclear over-expression of p16 (magnification, $\mathrm{x} 100$ ) and (G) negativity for CM2B4 antibody (magnification, x200), which was indicative of merkel cell poliomavirus virus negativity.

For case 2, that exhibited only neuroendocrine component, undifferentiated carcinoma of the lower uterine segment (LUS), which accounts for $6 \%$ of all endometrial cancers (37), was excluded by MRI, by the presence of HPV DNA and p16 immunoreactivity, demonstrating that the neoplasm does not originate from this segment of the uterus. Conversely, neuroendocrine markers may not be useful for the differential diagnosis, in this case, since undifferentiated carcinomas of the LUS may occasionally display focal positivity for neuroendocrine markers (38).

As well as for case 2, differential the diagnosis of SCNEC and embryonal rhabdomyosarcoma can be made because, under normal circumstances, this do not stain positive for cytokeratin and neuroendocrine markers $(39,40)$.

In case 2, primary lymphoma of the cervix, which is an exceedingly rare neoplasm (41) and typically consist of diffuse large B-cell lymphoma (DLBCL) (42) was excluded for morphological analysis and immunophenotyping. In fact, tumor cells in DLBCL generally express pan B-cell antigens (CD19, CD20, CD22 and CD79a) and are negative for neuroendocrine markers (42).
The possibility of SCNEC developing as a metastasis from other sites, such as the lungs and gastro-enteropancreatic tract must be ruled out. That said, isolated metastatic involvement of the cervix does appear to be exceedingly rare. For example, the most common sites of distant metastases from small cell carcinomas of the lung are the liver, adrenal glands, bones and brain. Moreover, the identification of a synchronous cervical neoplasia, such as H-SIL and cervical adenocarcinoma in close proximity to the neuroendocrine tumor, may also be useful to exclude the metastatic nature of neuroendocrine neoplasms arising in the cervix. In the present report, foci of H-SIL and foci of invasive cervical adenocarcinoma of usual type in case 1 and case 3 were observed.

SCNEC is frequently associated with HPV infections $(5,6)$. Given that MCPyV has been observed in a series of squamous cervical carcinomas and cervical adenocarcinomas in Japanese patients (17), as well as in certain neuroendocrine neoplasms, such as MCC of the skin, the present study employed immunohistochemical and PCR analysis, and the presence of MCPyV in all 3 cases of SCNEC of the cervix 

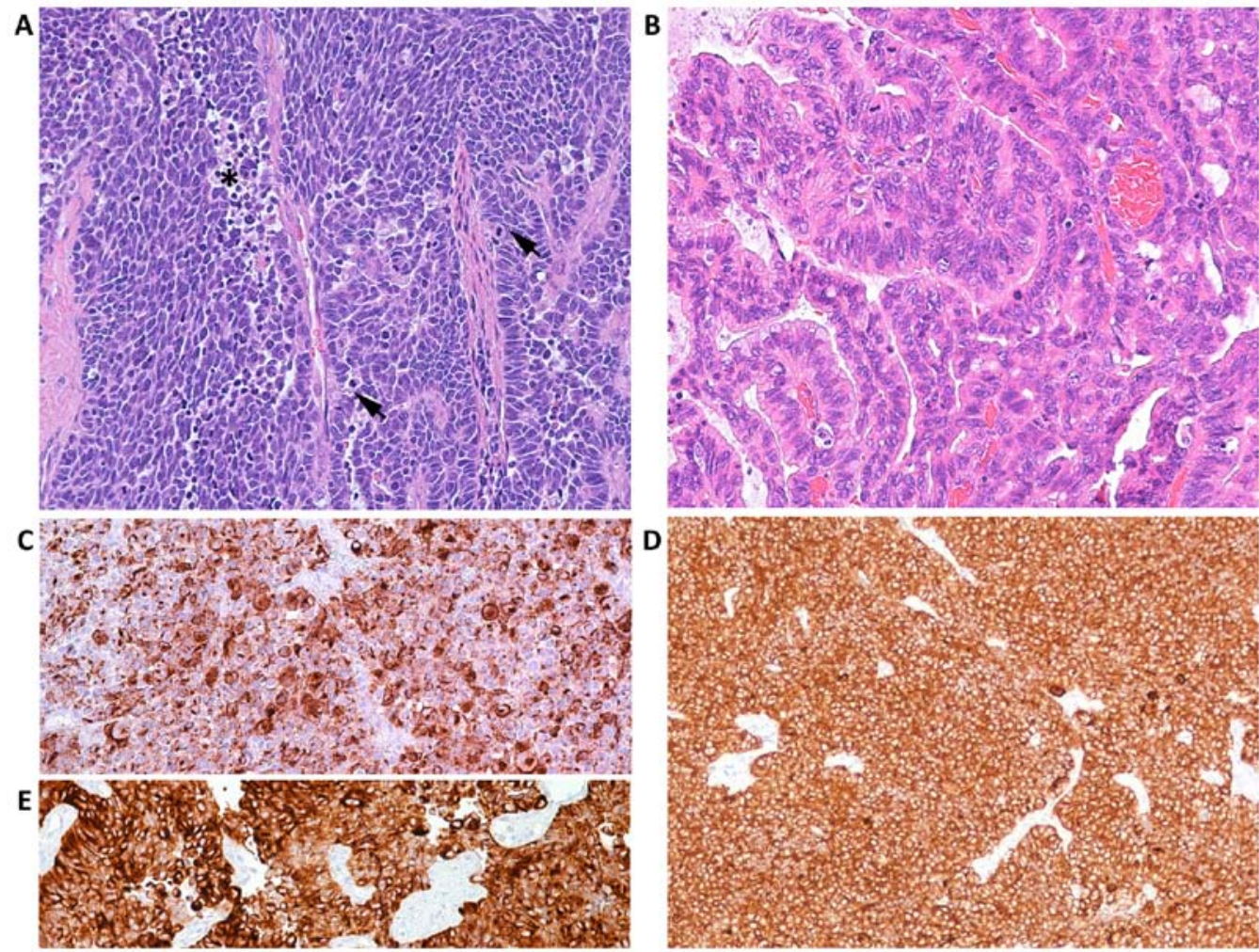

Figure 5. Case 3. Histologically, the neoplasm consisted of two components. (A) The neuroendocrine component was characterized by cords and trabecula of oval to spindle-shaped cells, with scant cytoplasm and numerous mitoses (arrows) and individual cell necrosis with karyorrhexis and karyolysis (asterisk) (magnification, x200). (B) The second component exhibited well-differentiated cervical adenocarcinoma (magnification, x200). (C) Using immunohistochemistry, the neuroendocrine component exhibited granular, dot-like perinuclear citoplasmic positivity for chromogranin A (magnification, x200). (D) Intense membrane immunoreactivity for synaptophysin was demonstrated (magnification, x100). (E) Membrane and cytoplasmic positivity for CAM5.2 was also revealed (magnification, $\mathrm{x} 200)$.

was assessed to determine whether this virus can coexist with HPV in this rare neoplasm. In the present study, HPV DNA was demonstrated in all three neuroendocrine carcinomas investigated and in the adenocarcinomatous component in the two mixed cases by PCR analysis. However, the lack of sequencing of the amplicon obtained by PCR in either neoplastic tissue or positive control represents a limitation of the present study. As well as, it may be a limtitation does not know viral load in these patients. Conversely, the positivity for p16 observed in all these cases and all components of the neoplasms, allows to establish that HPV detected corresponded to high-risk HPV (43).

In addition to the immunohistochemical study, in order to detect the presence of MCPyV DNA, PCR analysis, using a primer set was performed (19), as Moshiri et al (44) demonstrated that the immunohistochemistry alone was insufficient to classify a tumor as positive for virus (44). In fact, they evaluated the presence of MCPyV in a large series of MCC, using immunohistochemistry with two distinct antibodies and MCPyV DNA by PCR analysis, and concluded that a neoplasm can be considered MCPyV-positive when two or more of these three assays indicated the presence of this virus.

In the present study the immunoreactivity to cytokeratin 20 (CK20), which is expressed in more typical MCC (34), was verified. As CK20 immunoreactivity was negative, the present cases may be considered as non-Merkel neuroendocrine neoplasms. This finding may also explain the negativity to the CM2B4 monoclonal antibody in line with many cases reported by Glenn McCluggage et al (34) and in accordance with absence of MCPyV DNA as revealed by the combined use of immunohistochemical and PCR analysis.

In addition to the negativity for CK20 and CM2B4, in all three cases of the present study, we did not observe peri-tumoral inflammatory infiltrate, with CD8 positive cells, abnormal p53 expression and positivity for TTF1, which may be related with stage of neoplasms and prognosis, as reported by Kervarrec et al in many case of MCC (45). In fact, in case 1 the stage of neoplams was low and patient was alive and free of disease. Whilist, in cases 2 and case 3 the patients succumbed after a few months of diagnosis with diffuse metastatic disease.

Conclusions and future goals. In conclusion, these cases of SCNECs could suggest that they are non-Merkel neuroendocrine neoplasms and likely not associated with MCPyV, as revealed by the combined immunohistochemical and PCR analyses. However, in the cases of the present study, the absence of MCPyV may due to a genotype that was not detectable using the primers utilized for PCR analysis and the antibody used for immunohistochemimistry. Several studies, investigating the presence of $\mathrm{MCPyV}$ in $\mathrm{MCC}$ in different countries, have suggested that there are different MCPyV genotypes $(46,47)$. In fact, Martel-Jantin et al (46), using molecular analysis, demonstrated the existence of 5 major 

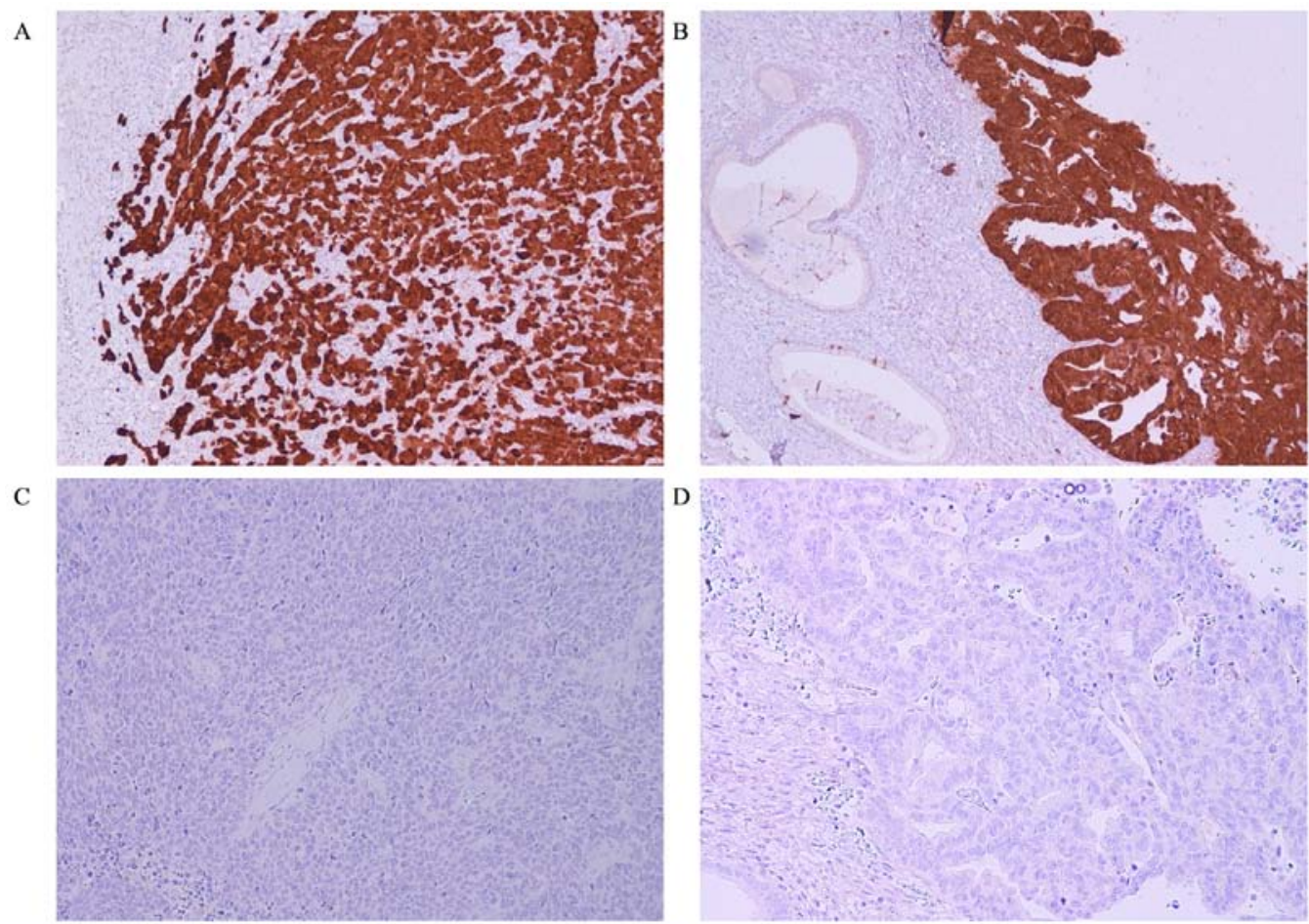

Figure 6. Case 3. Diffuse and marked immunohistochemical positivity for p16 protein were observed in both the (A) neuroendocrine (magnification, x100) and (B) adenocarcinomatous components (magnification, x100). (C) Negativity for merkel cell poliomavirus virus was observed in both the neuroendocrine (magnification, x200) and (D) adenocarcinomatous components (magnification, x200).

geographically related MCPyV genotypes (Europe/North America, Africa [sub-Saharan], Oceania, South America, and Asia/Japan] (44). Additionally, Matsushita et al (47) have suggested that MCPyV strains in Japanese MCC are distinct from MCPyVs genotypes associated with Caucasian populations (47).

As well as the lack of large $\mathrm{T}$ antigen expression in the present case series may reflect the presence of MCPyV microRNA that inhibits LT expression (48). Additional studies with larger cohorts cases and more advanced molecular biology techniques may be useful in evaluating the presence of MCPyV. Using more advanced molecular techniques, it may be possible to detecte MCPyV-associated microRNAs (miRNAs), which have the ability to autoregulate viral gene expression (48) allowing for improved identification in MCPyV-positive and MCPyV-negative SCNECs, and these techniques may allow for identification of a subset of miRNAs associated with tumor metastasis and specific survival, similarly to cases of MCCs (49).

As well as, further studies with larger cohorts cases of SCNEC of the cervix, may confirm that the expression for CK20, positivity for TTF1, abnormal expression for $\mathrm{p} 53$, negativity for CM2B4, and absence of inflammatory infiltrate, with $\mathrm{CD} 8$ positive cells may be related with advanced stage and poor prognosis of the neoplams, similarly to many cases of MCC (45).

\section{Acknowledgements}

The authors would like to thank Mrs Gabriella Becchi (Department of Medicine and Surgery, Pathology Unit, University of Parma, Italy) for her technical assistance.

\section{Funding}

The present study was funded by FIL Parma University.

\section{Availability of data and materials}

The data sets used and/or data analyzed during the present study are available from the corresponding author on reasonable request.

\section{Authors' contributions}

GGi and TDA conceived the study and wrote the manuscript. SP and NC performed molecular and immunohistochemical studies. GGa provided the clinical data and RB performed the surgery. GGi and RB declare the authenticity of the all raw data. All authors have read and approved the final manuscript.

\section{Ethics approval and consent participate}

The present study was approved by Ethics Committee of the Parma University Hospital (approval no. 26600).

\section{Patient consent for publication}

The informed consent was obtained from all individual participants except for the cases 2 and 3 due to their death and the inability to contact their relatives who do not reside in Italy.

\section{Competing interests}

The authors declare that they have no competing interests. 


\section{References}

1. Dikmen Y, Kazandi M, Zekioglu O, Ozsaran A, Terek MC and Erhan Y: Large cell neuroendocrine carcinoma of the uterine cervix: A report of a case and review of the literature. Arch Gynecol Obstet 270: 185-188, 2004.

2. Kim JY, Hong SM and Ro JY: Recent updates on grading and classification of neuroendocrine tumors. Ann Diagn Pathol 29: $11-16,2017$.

3. Albores-Saavedra J, Gersell D, Gilk CB, Henson DE, Lindberg G, Santiago H, Scully RE, Silva E, Sobin LH, Tavassoli FJ, et al: Terminology of endocrine tumors of the uterine cervix: Results of a work-shop sponsored by College of American Pathologists and the National Cancer Institute Arch Lab 121: 34-39, 1997.

4. Cree IA, Malpica A and McCluggage WG: Neuroendocrine neoplasia in WHO classification of femal genital Tumours 5th edition. Lyon, IARC, pp452-458, 2019.

5. Ambros RA, Park JS, Shah KV and Kurman RJ: Evaluation of histologic, morphometric, and immunohistochemical criteria in the differential diagnosis of small cell carcinomas of the cervix with particular reference to human papillomavirus types 16 and 18. Mod Pathol 4: 586-593, 1991.

6. Stoler MH, Mills SE, Gersell DJ and Walker AN: Small-cell neuroendocrine carcinoma of the cervix. A human papillomavirus type 18-associated cancer. Am J Surg Pathol 15: 28-32, 1991.

7. Li P, Ma J, Zhang X, Guo Y, Liu Y, Li X, Zhao D and Wang Z: Cervical small cell carcinoma frequently presented in multiple high risk HPV infection and often associated with other type of epithelial tumors. Diagn Pathol 13: 31-40, 2018.

8. Bolognia J, Jorizzo JL, Rapini RP, Callen JP, Horn TD, Mancini AJ, Salasche SJ, Schaffer JV, Schwarz T, Stingl G and Stone MS: Dermatology (2nd edition). St. Louis, MO, Mosby/Elsevier, 2008.

9. Feng H, Shuda M, Chang Y and Moore PS: Clonal integration of a polyomavirus in human Merkel cell carcinoma. Science 319: 1096-1100, 2008.

10. Kervarrec T, Samimi M, Guyétant S, Sarma B, Chéret J, Blanchard E, Berthon P, Schrama D, Houben R and Touzé A: Histogenesis of merkel cell carcinoma: A comprehensive review. Front Oncol 9: 451, 2019.

11. Bialasiewicz S, Lambert SB, Whiley DM, Nissen MD and Sloots TP: Merkel cell polyomavirus DNA in respiratory specimens from children and adults. Emerg Infect Dis 15 492-494, 2009

12. Goh S, Lindau C, Tiveljung-Lindell A and Allander T: Merkel cell polyomavirus in respiratory tract secretions. Emerg Infect Dis 15: 489-491, 2009.

13. Babakir-Mina M, Ciccozzi M, Lo Presti A, Greco F, Perno CF and Ciotti M: Identification of Merkel cell polyomavirus in the lower respiratory tract of Italian patients. J Med Virol 82: 505-509, 2010.

14. Abedi Kiasari B, Vallely PJ and Klapper PE: Merkel cell polyomavirus DNA in immunocompetent and immunocompromised patients with respiratory disease. J Med Virol 83: 2220-2224, 2011.

15. Wieland U, Mauch $\mathrm{C}$, Kreuter A, Krieg $\mathrm{T}$ and Pfister $\mathrm{H}$ Merkel cell polyomavirus DNA in persons without Merkel cell carcinoma. Emerg Infect Dis 15: 489-491, 2009.

16. Wieland U and Kreuter A: Merkel cell polyomavirus infection and Merkel cell carcinoma in HIV-positive individuals. Curr Opin Oncol 23: 488-493, 2011.

17. Imajoh M, Hashida Y, Nemoto Y, Oguri H, Maeda N, Furihata M, Fukaya T and Daibata M: Detection of Merkel cell polyomavirus in cervical squamous cell carcinomas and adenocarcinomas from Japanese patients. Virol J 9: 154, 2012.

18. Li J, Gerhard DS, Zhang Z, Huettner PC, Wright J, Nguyen L, Lu D and Rader JS: Denaturing high-performance liquid chromatography for detecting and typing genital human papillomavirus. J Clin Microbiol 41: 5563-5571, 2003.

19. Alvarez-Argüelles ME, Melón S, Rojo S, Fernandez-Blázquez A, Boga JA, Palacio A, Vivanco B and de Oña M: Detection and quantification of Merkel cell polyomavirus. Analysis of Merkel cell carcinoma cases from 1977 to 2015. J Med Virol 89: 2224-2229, 2017.

20. Kloppel G, Perren A and Heitz PU: The gastroenteropancreatic neuroendocrine cell system and its tumors: The WHO classification. Ann N Y Acad Sci 1014: 13-27, 2004
21. Plöckinger U, Rindi G, Arnold R, Eriksson B, Krenning EP, de Werder WW, Goede A, Caplin M, Oberg K, Reubi JC, et al: Guidelines for the diagnosis and treatment of neuroendocrine gastrointestinal tumours. A consensus statement on behalf of the European Neuroendocrine Tumour Society (ENETS). Neuroendocrinology 80: 394-424, 2004.

22. Yeh YC and Chou TY: Pulmonary neuroendocrine tumors: Study of 90 cases focusing on clinicopathological characteristics, immunophenotype, preoperative biopsy, and frozen section diagnoses. J Surg Oncol 109: 280-286, 2014.

23. Guadagno E, De Rosa $G$ and Del Basso De Caro M: Neuroendocrine tumours in rare sites: Differences in nomenclature and diagnostics-a rare and ubiquitous histotype. J Clin Pathol 69: 563-574, 2016.

24. van Nagell JR Jr, Powell DE, Gallion HH, Elliott DG, Donaldson ES, Carpenter AE, Higgins RV, Kryscio R and Pavlik EJ: Small cell carcinoma of the uterine cervix. Cancer 62: 1586-1593, 1988

25. Sevin BU, Method MW, Nadji M, Lu Y and Averette HA: Efficacy of radical hysterectomy as treatment for patients with small cell carcinoma of the cervix. Cancer 77: 1489-1493, 1996.

26. Conner MG, Richter H, Moran CA, Hameed A and Albores-Saavedra J: Small cell carcinoma of the cervix: A clinicopathologic and immunohistochemical study of 23 cases. Ann Diagn Pathol 6: 345-348, 2002.

27. Chen J, Macdonald OK and Gaffney DK: Incidence, mortality, and prognostic factors of small cell carcinoma of the cervix. Obstet Gynecol 111: 1394-1402, 2008.

28. Viswanathan AN, Deavers MT, Jhingran A, Ramirez PT, Levenback C and Eifel PJ: Small cell neuroendocrine carcinoma of the cervix: outcome and patterns of recurrence. Gynecol Oncol 93: 27-33, 2004

29. Abeler VM, Holm R, Nesland JM and Kjørstad KE: Small cell carcinoma of the cervix. A clinicopathologic study of 26 patients. Cancer 73: 672-677, 1994.

30. Alphandery C, Dagrada G, Frattini M, Perrone F and Pilotti S: Neuroendocrine small cell carcinoma of the cervix associated with endocervical adenocarcinoma: A case report. Acta Cytol 51: 589-593, 2007.

31. Zhou J, Wu SG, Sun JY, Tang LY, Lin HX, Li FY, Chen QH, Jin X and He ZY: Clinicopathological features of small cell carcinoma of the uterine cervix in the surveillance, epidemiology, and results database. Oncotarget 8: 40425-40433, 2017.

32. Chan JK, Loizzi V, Burger RA, Rutgers J and Monk BJ: Prognostic factors in neuroendocrine small cell cervical carcinoma, a multivariate analysis. Cancer 97: 568-574, 2003

33. Chang TC, Lai CH, Tseng CJ, Hsueh S, Huang KG and Chou HH Prognostic factors in surgically treated small cell cervical carcinoma followed by adjuvant chemotherapy. Cancer 83 : 712-718, 1998.

34. McCluggage WG, Kennedy K and Busam KJ: An immunohistochemical study of cervical neuroendocrine carcinomas: Neoplasms that are commonly TTF1 positive and which may express CK20 and P63. Am J Surg Pathol 34: 525-532, 2010.

35. Zhang C, Schmidt LA, Hatanaka K, Thomas D, Lagstein A and Myers JL: Evaluation of napsin, A; TTF-1, p63, p40, and CK5/6 immunohistochemical stains in pulmonary neuroendocrine tumors. Am J Clin Pathol 142: 320-324, 2014.

36. Tatsumori T, Tsuta K, Masai K, Kinno T, Taniyama T, Yoshida A, Suzuki K and Tsuda H: p40 is the best marker for diagnosing pulmonary squamous cell carcinoma: Comparison with p63, cytokeratin 5/6, desmocollin-3, and sox2. Appl Immunohistochem Mol Morphol 22: 377-382, 2014.

37. Masuda K, Banno K, Yanokura M, Kobayashi Y, Kisu I, Ueki A, Ono A, Nomura H, Hirasawa A, Susumu N and Aoki D: Carcinoma of the lower uterine segment (LUS): Clinicopathological characteristics and association with Lynch syndrome. Curr Genomics 12: 25-29, 2011.

38. Rabban JT and Zaloudek CJ: Neuroendocrine differentiation in endometrial tumors: A practical diagnostic approach. Pathol Case Rev 16: 119-125, 2011

39. Sebire NJ and Malone M: Myogenin and MyoD1 expression in paediatric rhabdomyosarcomas. J Clin Pathol 56: 412-416, 2003.

40. Dehner LP, Jarzembowski JA and Hill DA: Embryonal rhabdomyosarcoma of the uterine cervix: A report of 14 cases and a discussion of its unusual clinicopathological associations. Mod Pathol 25: 602-614, 2012.

41. Upanal N and Enjeti A: Primary lymphoma of the uterus and cervix: Two case reports and review of the literature. Aust N Z J Obstet Gynaecol 51: 559-562, 2011 
42. Cubo AM, Soto ZM, Cruz MÁ, Doyague MJ, Sancho V, Fraino A, Blanco Ó, Puig N, Alcoceba M, González M and Sayagués JM: Primary diffuse large B cell lymphoma of the uterine cervix successfully treated by combined chemotherapy alone: A case report. Medicine (Baltimore) 96: e6846, 2017.

43. Kalof $\mathrm{AN}$ and Cooper K: p16INK4a immunoexpression: Surrogate marker of high-risk HPV and high-grade cervical intraepithelial neoplasia. Adv Anat Pathol 13: 190-194, 2006

44. Moshiri AS, Doumani R, Yelistratova L, Blom A, Lachance K, Shinohara MM, Delaney M, Chang O, McArdle S, Thomas H, et al Polyomavirus-negative Merkel cell carcinoma: A more aggressive subtype based on analysis of 282 cases using multimodal tumor virus detection. J Invest Dermatol 137: 819-827, 2017.

45. Kervarrec T, Samimi M, Gaboriaud P, Gheit T, Beby-Defaux A, Houben R, Schrama D, Fromont G, Tommasino M, Le Corre Y, et al: Detection of the Merkel cell polyomavirus in the neuroendocrine component of combined Merkel cell carcinoma. Virchows Arch 472: 825-837, 2018.

46. Martel-Jantin C, Filippone C, Tortevoye P, Afonso PV, Betsem E, Descorps-Declere S, Nicol JT, Touzé A, Coursaget P, Crouzat M, et al: Molecular epidemiology of merkel cell polyomavirus: Evidence for geographically related variant genotypes. J Clin Microbiol 52: 1687-90, 2014.
47. Matsushita M, Iwasaki T, Kuwamoto S, Kato M, Nagata K, Murakami I, Kitamura Y and Hayashi K: Merkel cell polyomavirus (MCPyV) strains in Japanese merkel cell carcinomas (MCC) are distinct from Caucasian type MCPyVs: Genetic variability and phylogeny of MCPyV genomes obtained from Japanese MCPyV-infected MCCs. Virus Genes 48: 233-242, 2014.

48. Seo GJ, Chen CJ and Sullivan CS: Merkel cell polyomavirus encodes a microRNA with the ability to autoregulate viral gene expression. Virology 383: 183-18, 2009.

49. Xie H, Caramuta S, Höög A, Browaldh N, Björnhagen V, Larsson C and Lui WO: MicroRNA expression patterns related to merkel cell polyomavirus infection in human merkel cell carcinoma. J Invest Dermatol 134: 507-517, 2014.

This work is licensed under a Creative Commons Attribution-NonCommercial-NoDerivatives 4.0 International (CC BY-NC-ND 4.0) License. 